\title{
CORRESPONDENCE
}

\section{Rats maintain a binocular field centered on the horizon}

\section{[version 1; peer review: 3 approved]}

\section{Markus Meister ${ }^{1}$, David Cox ${ }^{2}$}

${ }^{1}$ Division of Biology, California Institute of Technology, Pasadena, CA 91125, USA

${ }^{2}$ Department of Molecular and Cellular Biology, Center for Brain Science, Harvard University, Cambridge, MA 02138, USA

V1 First published: 16 Aug 2013, 2:176

https://doi.org/10.12688/f1000research.2-176.v1

Latest published: 16 Aug 2013, 2:176

https://doi.org/10.12688/f1000research.2-176.v1

\section{Abstract}

In this letter, we attempt to correct a potentially serious misperception arising from the paper "Rats maintain an overhead binocular field at the expense of constant fusion". While the authors repeatedly emphasize that the animal's binocular field is overhead, the authors' own data show that the truth is quite different, even orthogonal: the binocular field is in fact centered dead-ahead in front of the animal, tapering to a sliver both above and below the animal. We predict that this paper will be widely cited for something that it does not demonstrate, a concern that is borne out by the paper's earliest citation.

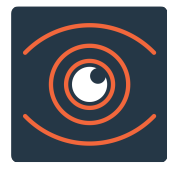

This article is included in the Eye Health

gateway.

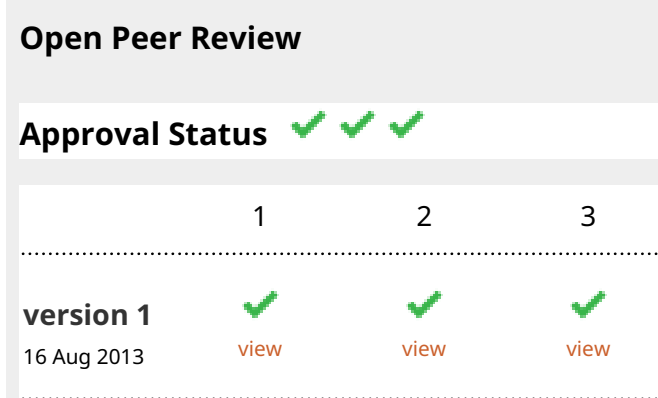

1. Matteo Carandini, University College

London, London, UK

2. Stephen Van Hooser, Brandeis University,

Waltham, MA, USA

3. Michael Land, University of Sussex, Brighton,

UK

Any reports and responses or comments on the article can be found at the end of the article.

Corresponding authors: Markus Meister (meister@caltech.edu), David Cox (davidcox@fas.harvard.edu)

Competing interests: No competing interests were disclosed.

Grant information: The author(s) declared that no grants were involved in supporting this work.

Copyright: $\odot 2013$ Meister M and Cox D. This is an open access article distributed under the terms of the Creative Commons Attribution License, which permits unrestricted use, distribution, and reproduction in any medium, provided the original work is properly cited. Data associated with the article are available under the terms of the Creative Commons Zero "No rights reserved" data waiver (CC0 1.0 Public domain dedication).

How to cite this article: Meister $M$ and Cox D. Rats maintain a binocular field centered on the horizon [version 1; peer review: 3 approved] F1000Research 2013, 2:176 https://doi.org/10.12688/f1000research.2-176.v1

First published: 16 Aug 2013, 2:176 https://doi.org/10.12688/f1000research.2-176.v1 


\section{Correspondence}

We wish to correct a potentially serious misperception that arises from the paper "Rats maintain an overhead binocular field at the expense of constant fusion" by Wallace et al., 2013 ${ }^{1}$. The title, the abstract and the discussion all emphasize the principal claim that the rat's eye movements "keep the visual fields of the two eyes continuously overlapping above the animal". The final sentence reads, "Instead, the movements keep the animal's binocular visual field above it continuously while it is moving". Many similar statements are found throughout the text and in the Editor's Summary. From this, a reader might easily conclude that a rat's binocular visual field is located overhead. However the truth is very different, and in fact orthogonal: the binocular field is primarily located dead ahead of the animal. As shown in Figure 5f of the same paper - where the vertical axis represents "overhead" in the conventional "opposite-to-gravity" sense of the word - the binocular field is a vertical sliver centered on the horizon, where it has the widest extent. It narrows towards the top and the bottom, and ends in a point at locations both above and below the animal.

Presumably the authors wanted to say that "the overhead direction is within the binocular field roughly $50 \%$ of the time", which would be more accurate given the data in Figure 5f. Of course the same is true for a direction pointing almost straight down towards the ground. Meanwhile, the direction in front of the animal is effectively always in the binocular field. Why the singular focus on "overhead"? The authors speculate about the need for binocular vision overhead for detecting predatory birds. This is unconvincing. First, only about a quarter of the overhead visual field is binocular (Figure 5f). Given the high cost of missing a predator, it seems the rat must have monocular ways of detecting one. Second, a major benefit of binocular vision is the opportunity for depth measurement by parallax. This works only for nearby objects, rather than distant birds, and would thus apply primarily to the visual field ahead or below the animal.

The authors conducted a behavioral study to reinforce the idea that rat vision is specialized for processing overhead threats, showing that rats seek shelter under an arch-shaped platform when a drifting bar appeared overhead, but not when it appeared on the side of their enclosure (Figure 6). While we hesitate to engage in behavioral just-so stories, we do note that different sheltering strategies probably exist for different kinds of threats (e.g. land-based and aerial), and that the rat might be wise not enter into a confined space with open sides, when a threat approaches from the side. It is likewise unclear if a drifting bar is equally perceived as a threat when presented above or beside the animal.

Regardless of such ethological speculations, we predict that the paper will be widely cited incorrectly for what it does not demonstrate, as a result of the misleading title and abstract. In fact, this has happened already in what is probably the article's first citation ${ }^{2}$.

\section{Author contributions}

MM wrote the first version of the letter and corresponded with the paper's senior author for clarification. MM and DDC participated in the discussion and revision of the letter.

\section{Competing interests}

No competing interests were disclosed.

\section{Grant information}

The author(s) declared that no grants were involved in supporting this work.
1. Wallace DJ, Greenberg DS, Sawinski J, et al: Rats maintain an overhead binocular field at the expense of constant fusion. Nature. 2013; 498(7452): 65-9. PubMed Abstract | Publisher Full Text Land MF: Animal vision: rats watch the sky. Curr Biol. 2013; 23(14):
R611-3.

PubMed Abstract | Publisher Full Text 


\section{Open Peer Review}

\section{Current Peer Review Status:}

\section{Version 1}

Reviewer Report 28 August 2013

https://doi.org/10.5256/f1000research.2132.r1589

(C) 2013 Land M. This is an open access peer review report distributed under the terms of the Creative Commons Attribution License, which permits unrestricted use, distribution, and reproduction in any medium, provided the original work is properly cited.

\section{Michael Land \\ University of Sussex, Brighton, UK}

I approve of the authors' commentary. The mistake in the original paper comes from a confusion where the binocular field is relative to the head, rather than where it is relative to gravity - which is actually the relevant measurement. Cox and Meister are right to point this out. It is certainly true that the field moves as the head moves, because of the compensatory eye movements, but it remains only partially overhead, and has its maximal extent in the forward direction.

Competing Interests: No competing interests were disclosed.

I confirm that I have read this submission and believe that I have an appropriate level of expertise to confirm that it is of an acceptable scientific standard.

Reviewer Report 22 August 2013

https://doi.org/10.5256/f1000research.2132.r1520

(C) 2013 Van Hooser S. This is an open access peer review report distributed under the terms of the Creative Commons Attribution License, which permits unrestricted use, distribution, and reproduction in any medium, provided the original work is properly cited.

\section{Stephen Van Hooser}

Brandeis University, Waltham, MA, USA

The present letter refers to a recent (2013) Nature article by Wallace, Greenberg, Sawinski, and colleagues entitled 'Rats maintain an overhead binocular field at the expense of constant fusion'. This Nature article is a tour-de-force examination of eye movements in freely moving rats. The authors created instrumentation and analysis methods to both examine eye movements and rotations, and head movements and rotations, while the rats behaved freely. They found the surprising result that the eyes do not maintain constant fusion, as they do in previously examined 
animals such as primates. Further, from their analysis of eye movements and head movements, the authors determined the most common region of binocular overlap as the animals wandered about their environment. In head-centric coordinates, this region of binocular overlap reached its greatest horizontal width at a location superior and rostral to the nose (Figure 5e). The authors work also shows that rats tend to keep their heads pitched downward as they move about. Therefore, in body-centric coordinates (using the spine to determine rostral, caudal, superior, inferior directions), this region of binocular overlap reaches its greatest horizontal width at a location directly rostral to the body (Figure $5 f$ ).

The present letter by Meister and Cox raises a legitimate and serious concern with the "big picture" language of the Wallace et al. paper. In the abstract, Wallace el al. report that "the observed eye movements serve to keep the visual fields of the two eyes continuously overlapping above the animal during free movement, but not continuously aligned". The coordinate system for the word "above" is not clear from context. Meister and Cox makes the important point that a substantial fraction of readers (perhaps an overwhelming majority) are likely to assume that "above" is in body-centric coordinates, and to make the erroneous interpretation that the binocular overlap is largest above the animal. That is, many readers will erroneously interpret this sentence to mean that the region of greatest binocular overlap is superior to the spine. This potential misinterpretation is made even more likely by the behavioral experiment reported in Wallace et al., where the authors provide visual stimulation above the spine. The letter writers also point out that there is no rigorous link between the behavioral experiment and the region of binocular overlap. While the behavioral result is interesting, it is unclear if the behavior has anything to do with binocular vision.

This letter by Meister and Cox makes a very important contribution. In my opinion, the letter could be improved by making clearer references to the coordinate system being used when a direction is mentioned. For example, the letter writers state "the binocular visual field is located dead ahead of the animal". The writers assume that the reader will intuit that body-centric coordinates are intended. However, some readers (such as the authors of Wallace et al.) may find it more natural to assume that head-centric coordinates are intended. I understand what the authors mean by "opposite-to-gravity"; the authors assume the animal is on its 4 legs. Referring to coordinate systems linked to the animal would be clearer, in my opinion.

Competing Interests: No competing interests were disclosed.

\section{I confirm that I have read this submission and believe that I have an appropriate level of expertise to confirm that it is of an acceptable scientific standard.}

Reviewer Report 19 August 2013

https://doi.org/10.5256/f1000research.2132.r1519

(C) 2013 Carandini M. This is an open access peer review report distributed under the terms of the Creative Commons Attribution License, which permits unrestricted use, distribution, and reproduction in any medium, provided the original work is properly cited. 


\section{Matteo Carandini}

Institute of Ophthalmology, University College London, London, UK

This commentary can perhaps be reconciled with the original paper by considering the meaning of 'overhead'. In the original paper, 'overhead' seems to mean literally 'above the head'. Because the head typically faces downward (compare Figures $5 e$ and 5f), that actually means 'in front of the animal'. I agree with the commentary that this is possibly a poor word choice: it will likely be interpreted by most readers as 'above the animal'.

Competing Interests: No competing interests were disclosed.

I confirm that I have read this submission and believe that I have an appropriate level of expertise to confirm that it is of an acceptable scientific standard.

The benefits of publishing with F1000Research:

- Your article is published within days, with no editorial bias

- You can publish traditional articles, null/negative results, case reports, data notes and more

- The peer review process is transparent and collaborative

- Your article is indexed in PubMed after passing peer review

- Dedicated customer support at every stage

For pre-submission enquiries, contact research@f1000.com 